\title{
An Analysis on the Transmission Shaft Fracture of Screw Drill
}

\author{
Bin LUO \\ School of Mechatronic Engineering, Southwest \\ Petroleum University, \\ Chengdu 610500, Sichuan Province, China \\ Gaofei LIU \\ School of Mechatronic Engineering, Southwest \\ Petroleum University, \\ Chengdu 610500, Sichuan Province, China \\ Jian DU \\ School of Mechatronic Engineering, Southwest Petroleum University, \\ Chengdu 610500, Sichuan Province, China
}

\begin{abstract}
The transmission shaft of the underground screw drill fractured when milling-shoe and grinding bridge plug was applied to the coiled tubes in a horizontal well of Sichuan province, but the position of this transmission shaft fracture did not occur at the minor-diameter retracting position and reducing position that were easy to fracture. An analysis of the transverse planes of the fracture found that the cause of the transmission shaft fracture surface was that the defects of the initial surface were propagating to cracks and gave rise to the fracture under torque load. To specifically know well the strength of the transmission shaft under damaging fracture, a statics analysis was conducted on the transmission shaft through
\end{abstract} ANSYS finite element simulation software, and the finite element models under no cracks, different-depth circumferential cracks, and similar situation of the transverse planes of fracture were established respectively. An analysis of the crack-free finite element model found that the fracture of the transmission shaft was really not caused by the self-structure of the transmission shaft; an analysis of circumferential crack finite element model found that strong stress concentration would appear in the tip of cracks, and the value of the stress would increase along with the increase of the circumferential crack depth, the stress of the entire crack top tended to fluctuate like waves, and also the strength of the transmission shaft was greatly impacted by the presence of cracks; an analysis of the similar crack finite element model found that stress concentration would appear in the tip of cracks, and the initial cracks always started to propagate from the tip of the external surface of the transmission shaft and would propagate inward until the propagating areas of two cracks overlapped, and finally reached the position of transient interruption, and then the transmission shaft fractured completely and the fracture strength was only $1 / 5$ of that under no cracks.

Keywords: Screw Drill; Transmission Shaft; Fracture Analysis; Crack; ANSYS

\section{Introduction}

Screw drill is a positive displacement downhole motor that converts mechanical energy using liquid pressure [1], and it is mainly composed of by-pass valve assembly, motor assembly, cardan shaft assembly, and transmission shaft assembly ${ }^{[1-4]}$. Transmission shaft is an important bridge to transfer the torque and rotational speed caused by the motor to the drill, for implementing the mutual influence and transmission of various dynamic and static loads.

Coiled tubing drilling and milling technology [5] means that the coiled tubing operation machine ${ }^{[6]}$, after sending the coiled tubes as well as the front-end drilling and grinding tool string to the targeted position, injects the operating liquid pump into the tool string for driving the screw motor to drive milling shoe to rotate, and then cuts the to-be-milled objects in a way of slipping deformation under extrusion through the reasonable control of working differential pressure and bit pressure, in which milling shoe 
eats the to-be-milled objects under the action of bit pressure and can move forward and cut the to-be-milled objects under the action of torque, and then the crushed objects rapidly deviate from the shaft bottom and flow into annular space under the impact of high-pressure water jet and driven to get out of the well hole through the circulation of the operating fluid, for the purpose of ensuring the well home unblocked, the production layers connected, and the exploiting efficiency improved.

The transmission shaft of the underground screw drill fractured when milling-shoe and grinding bridge plug was applied to the coiled tubes with screw drill [7] in a horizontal well of Sichuan province, and the fractured segment and milling shoe of the transmission shaft were not refloated successfully, and ultimately the sealed reservoir was only developed by side tracking, thus causing a huge economic loss. An analysis of the fracture of the reclaimed transmission shaft found that the position of this transmission shaft fracture did not occur at the minor-diameter retracting position [8] and reducing position [3] [9] that were easy to fracture, and an analysis of the transverse planes of the fracture found that the cause of this transmission shaft fracture was that the initial crack of the transmission shaft propagated to cracks and gave rise to the fracture [10]. To clearly know the stress of the transmission shaft under the fracture, a statics analysis on the transmission shaft was conducted using ANSYS finite element analysis tool [11].

\section{Mechanical model}

Because of the complexity and uncertainty of the working conditions, it is very difficult to determine the operating conditions of screw drill. The operating condition of the transmission shaft as one of the important parts of screw drill is very difficult to analyze accurately, and a comprehensive analysis on its operating condition is almost impossible. According to the working principle of screw drill, information query and field survey, the mechanical model of the transmission shaft was concluded as shown in (a) of Fig.1: it was mainly composed of mechanical torque $(M)$, lateral force $\left(R_{b}\right)$, and axial force $\left(\mathrm{P}_{\mathrm{T}}\right)^{[12-13]}$, in which torque load played a great effect on the transmission shaft [3]. Therefore, in this paper, the fracture of the transmission shaft was analyzed under the torque load. $\mathrm{M}$ was mainly composed of rotary torque $(\mathrm{Mz})$ and motor torque $(\mathrm{Mp})$. Because coiled tubes with screw drill were applied to the studied horizontal well of Sichuan province, $\mathrm{Mz}$ could be regarded as 0 and only $\mathrm{Mp}$ was considered. The specific dimension of the transmission shaft was as shown in (b) of Fig.1: $\mathrm{D}=89 \mathrm{~mm}, \mathrm{~d}_{1}=44.4 \mathrm{~mm}$, and $\mathrm{d}_{2}=15 \mathrm{~mm}$.

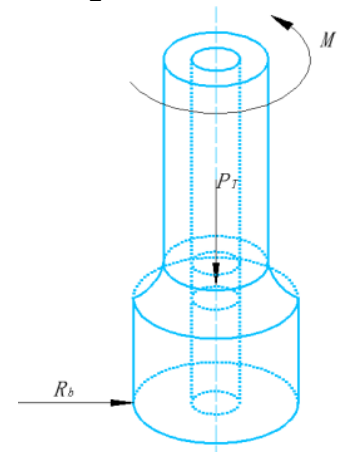

(a)

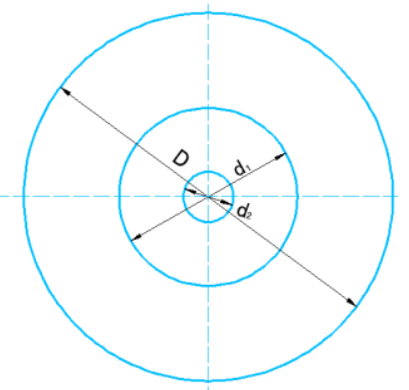

(b)
Fig1. Diagram of the transmission shaft force and specific size

\section{The finite element model and the analysis of the results}

In this paper, the screw drill used in a horizontal well of Sichuan province was taken for example: the operating torque was in $0.9-1.5 \mathrm{KN} \cdot \mathrm{m}$ and the effect of the transmission shaft under torque load was mainly studied. The material of the transition shaft was AISI $4330 \mathrm{~V}$ MOD, the constant of the material was the Young's modulus $(\mathrm{E}=206 \mathrm{GPa})$, Poisson's ratio was $\mathrm{u}=0.3$, and the yield limit was $\sigma s=890 \mathrm{Mpa}$. It was assumed that the material was isotropic and linearly elastic; the bottom of the transmission shaft was fixed, and the transmission shaft suffered cracks if the stress reached the yield limit. For mesh generation, 10-node linear strain tetrahedron element was used. 
In order to better study the effect of cracks on the transmission shaft, finite element models under three conditions were established in this paper: (1) finite element model without the cracks of the transmission shaft; (2) finite element model with the circumferential cracks of the transmission shaft; (3) finite element model with the similar situation of the transmission shaft fracture.

\subsection{The result and analysis of the finite element model without cracks}

In the finite element model without the cracks of the transmission shaft, different torque load was chosen to examine the stress of the fracture position of the transmission shaft, and the stress of the fracture position of the transmission shaft under $1 \mathrm{KN} \cdot \mathrm{m}$ torque load was as shown in Fig.2 and the maximum of the stress was $162.35 \mathrm{MPa}$. The fracture position was chosen as a path to examine the stress under different load, and also the stress on this path was mapped into the actual circular loop and the result was as shown in Fig.3: under the same load condition, the stress on the circular loop of the transmission shaft was not identical, but tended to increase along with the increase of the load; the maximum stress was up to $811.75 \mathrm{MPa}$ under $5 \mathrm{KN} \cdot \mathrm{m}$ work load and then could approach the yield limit. Overall, the stress of the transmission shaft under work load was much lower than the yield limit of the material and the shaft could work normally. Therefore, it was seen that the cause of the fracture of this position was really not the self-structure of the transmission shaft.

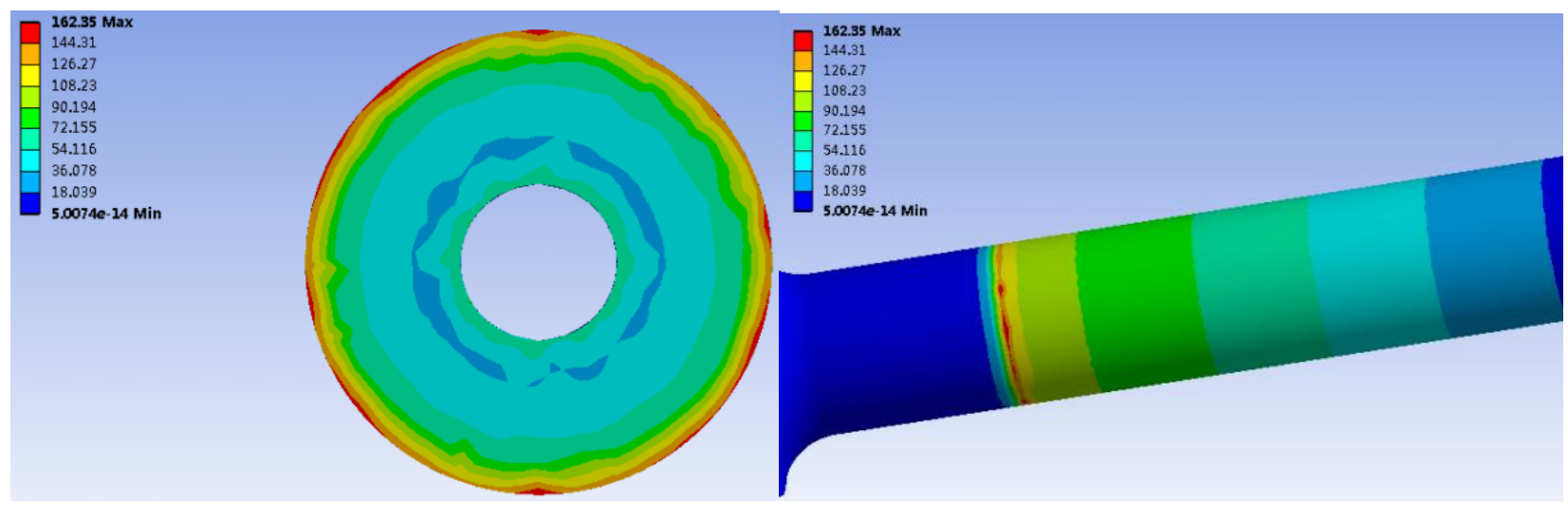

Fig.2 Diagram of stress under $1 \mathrm{KN} \bullet \mathrm{m}$ torque load without crack 


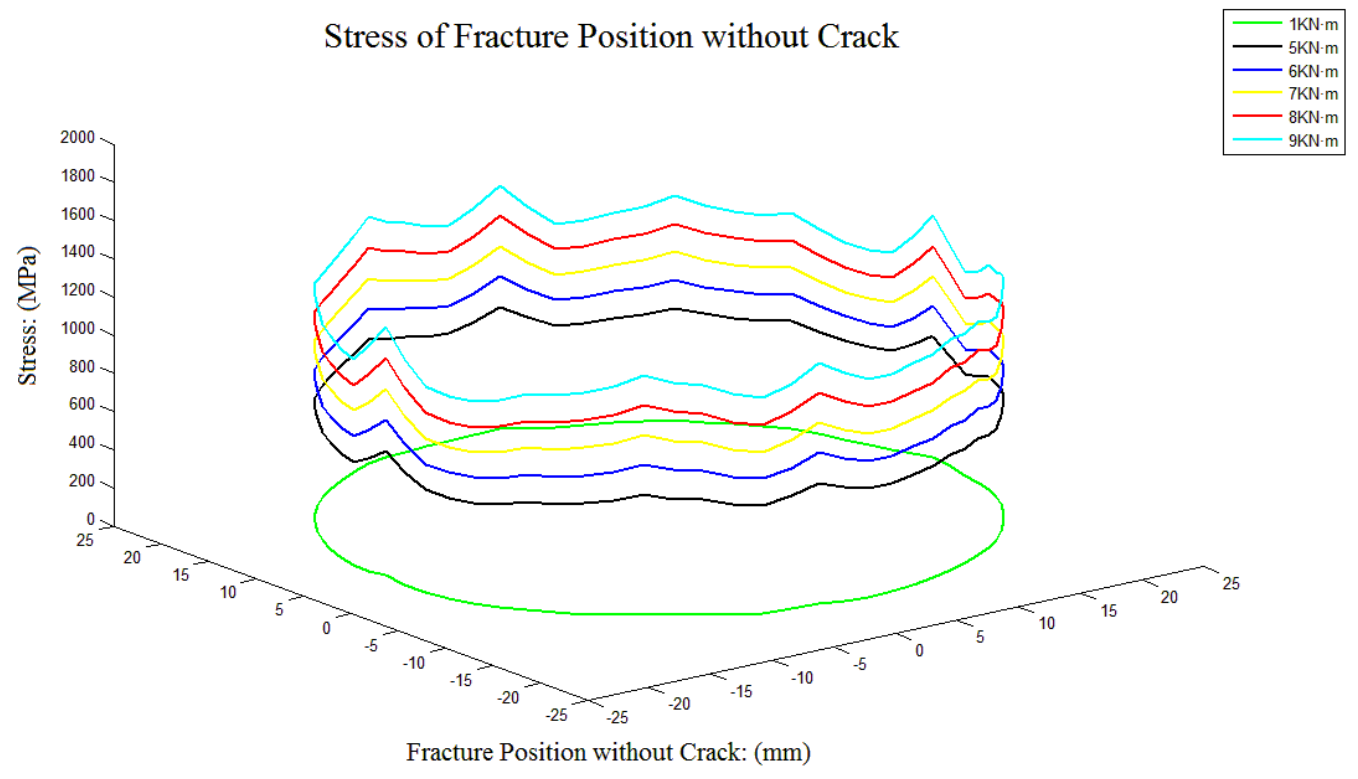

Fig.3 Diagram of stress of break circle line under different torque load

\subsection{The result and analysis of the finite element model with circumferential crack}

This type of complex crack is first approximated as the circumferential crack of the transmission shaft because the cracks on the transverse planes of the fracture of the transmission shaft are very complex. It was assumed that the operation torque of the transmission shaft was $1 \mathrm{KN} \cdot \mathrm{m}$ and then the stress of the transmission shaft was as shown in Figu. 4 if the circumferential depth was $3.2 \mathrm{~mm}$ : the maximum stress was $937.16 \mathrm{MPa}$ and exceeded the material's yield limit, if stress concentration appeared in the crack tip, and therefore, the effect of crack on the strength of the shaft was great. Under $1 \mathrm{KN} \cdot \mathrm{m}$ load, the stress of differently deep circumferential cracks at the fracture position could be examined, founding serious stress concentration occurred in the tip of the circumferential crack. The stress of the circular loop of the circumferential crack was extracted as shown in Fig.5: the stress in the tip was not always a fixed value and also changed more greatly under the condition of no crack, but generally increased along with the increase of the depth of the circumferential crack. Under $1 \mathrm{KN} \cdot \mathrm{m}$ torque load, the stress of the circumferential crack increased a lot, compared with the condition of no crack.
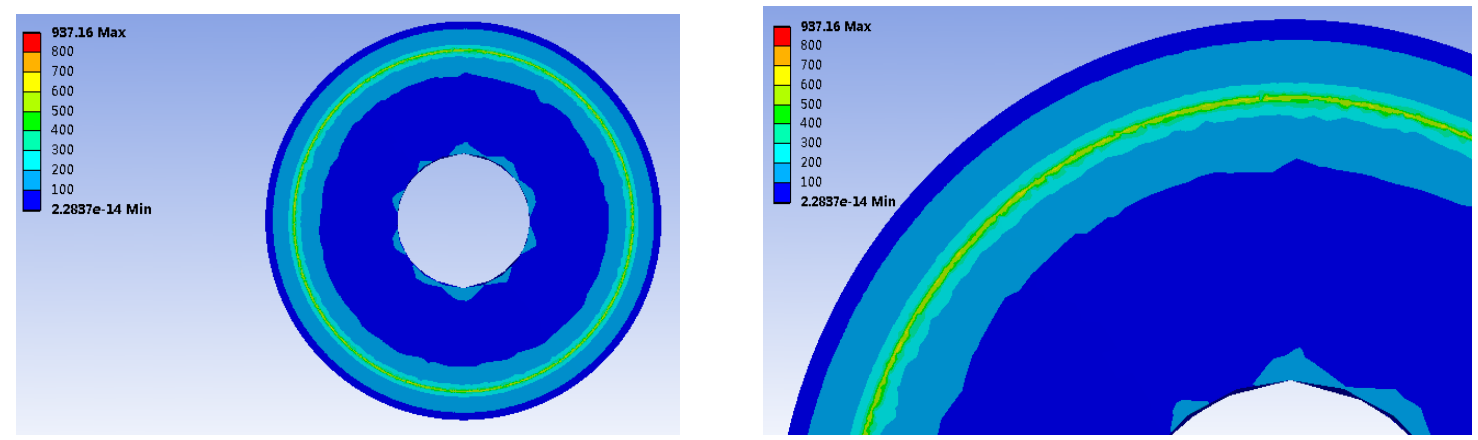

Fig.4 Diagram of stress under $1 \mathrm{KN} \bullet \mathrm{m}$ torque load with circumferential crack of depth in $3.2 \mathrm{~mm}$ 


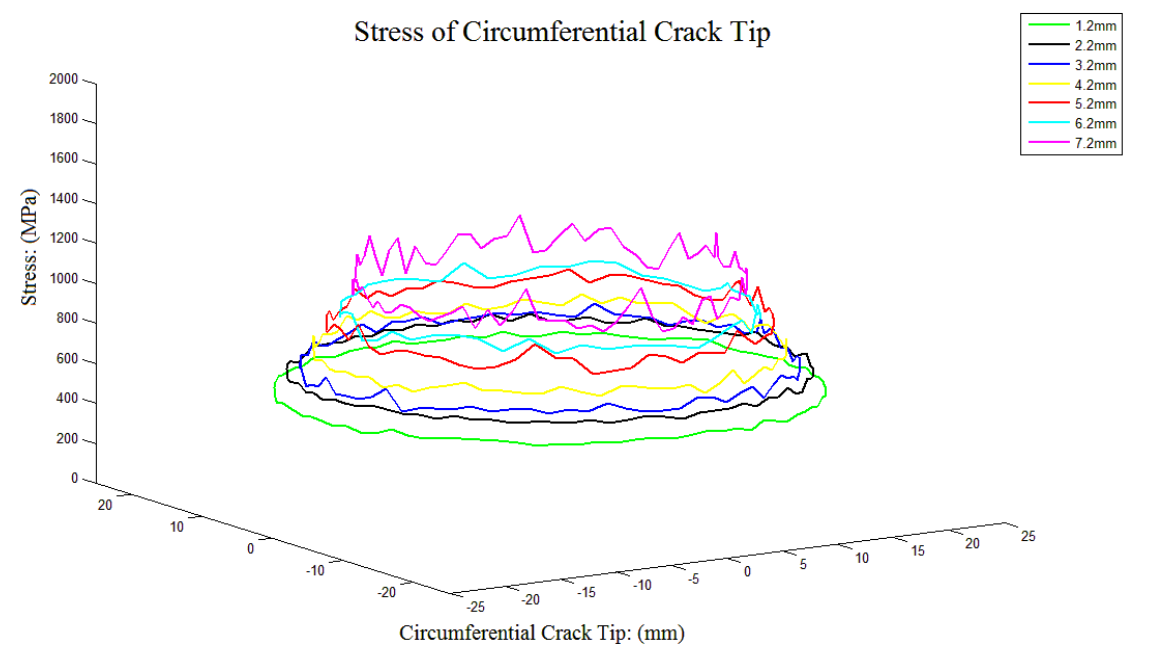

Fig.5 Diagram of stress of circumferential crack tip under different $1 \mathrm{KN} \bullet \mathrm{m}$ torque load with different depth

\subsection{The result and analysis of the finite element model with the similar situation of fracture}

After several fatigue cracks propagate the defects of the initial surface in any shapes, semi-elliptical cracks will develop ${ }^{[14-15]}$. By carefully studying the transverse planes of the transmission shaft fracture of the screw drill recycled to the ground as shown in Fig.6, it was seen that 5 propagating cracks existed on the transverse planes, and these cracks could be approximated as the situation in Fig. 6 after their sizes were measured. The transmission shaft with similar crack was analyzed with ANSYS finite element software, and its stress was as shown in Fig.7 under $1 \mathrm{KN} \cdot \mathrm{m}$ torque load, from which stress concentration obviously existed on the rip of crack like circumferential crack, but the maximum stress of the transmission shaft under $1 \mathrm{KN} \cdot \mathrm{m}$ torque load had far exceeded the yield limit of the material. Therefore, it was not hard to see that the strength of the transmission shaft of screw drill under crack would be greatly reduced.
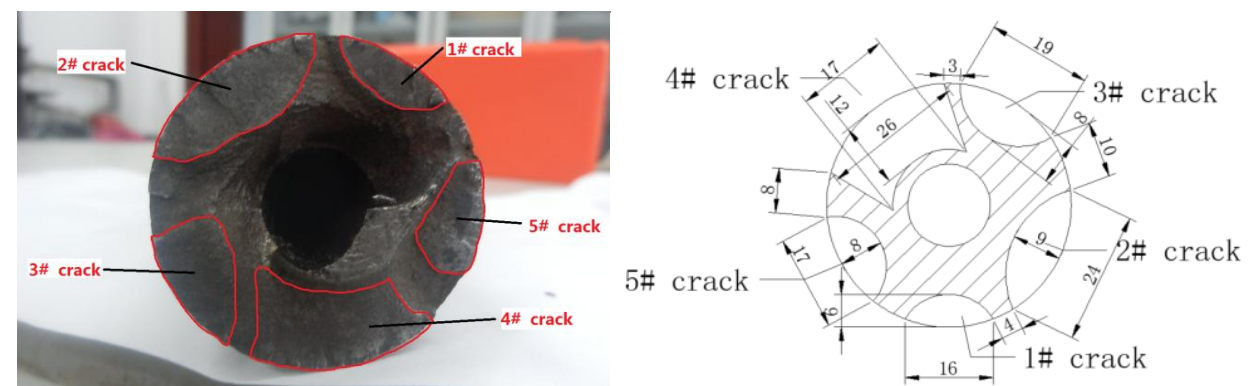

Fig.6 Diagram of crack distribution and size of transmission shaft fracture surface 


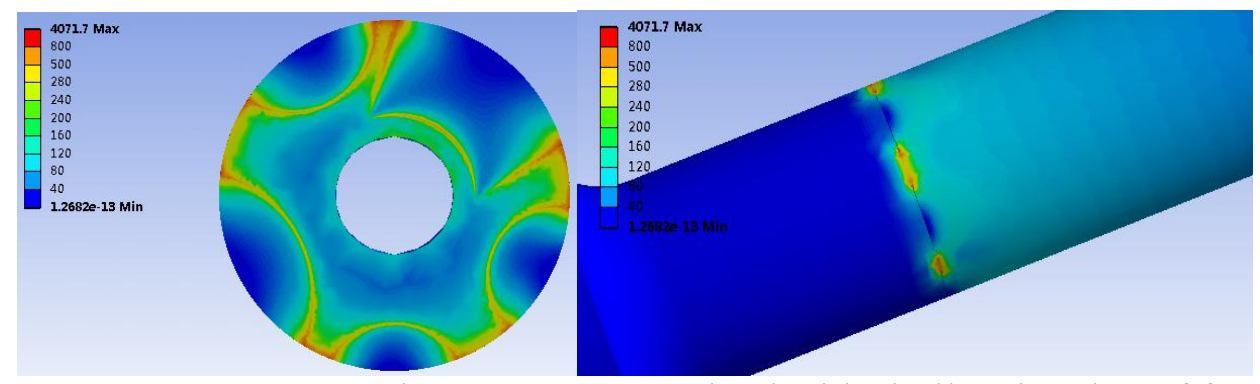

Fig.7 Diagram of stress under $1 \mathrm{KN} \bullet \mathrm{m}$ torque load with similar situation of fracture

The stress of the fracture surface under different torque was checked after the torque load of transmission shaft was reduced, as shown in Fig.8, the upper torque loads from left to right in turn were $0.2 \mathrm{KN} \bullet \mathrm{m}, 0.3 \mathrm{KN} \cdot \mathrm{m}, 0.4 \mathrm{KN} \bullet \mathrm{m}$, and $0.5 \mathrm{KN} \cdot \mathrm{m}$, and the lower torque loads from left to right in turn were $0.6 \mathrm{KN} \cdot \mathrm{m}, 0.7 \mathrm{KN} \cdot \mathrm{m}, 0.8 \mathrm{KN} \bullet \mathrm{m}$, and $0.9 \mathrm{KN} \bullet \mathrm{m}$. From Fig.8, it was seen that the maximum stress under $0.2 \mathrm{KN} \cdot \mathrm{m}$ torque load had reached $814.34 \mathrm{Mpa}$, while the maximum stress was $1221.5 \mathrm{MPa}$ under $0.3 \mathrm{KN} \cdot \mathrm{m}$ torque load, far exceeding the yield limit of the material. Therefore, it was thought that the transmission shaft could work normally only under $0.2 \mathrm{KN} \bullet \mathrm{m}$ torque load, down to $1 / 5$ of the original compared with $1 \mathrm{KN} \cdot \mathrm{m}$ working load, or the strength of the transmission shaft was down to $1 / 5$ of the original under similar situation of fracture. From Fig.8, it was seen that stress concentration still appeared on the tip of crack, and the maximum stress appeared on the position between different cracks close to the external surface of the transmission shaft and would increase gradually as it was approximated to the working load, and simultaneously the stress on the tip of crack from outside to inside was larger and larger. Therefore, a conclusion as follows was made: the initial cracks always began to propagate from the external surface of the transmission shaft and then spread inward, and they gradually grew and propagate inward together until the propagating areas of two different cracks overlapped and ultimately reached the position of transient interruption, and then the transmission shaft fractured completely. From Fig.6, one transient interruption belt on the transmission shaft was seen ${ }^{[9]}$.

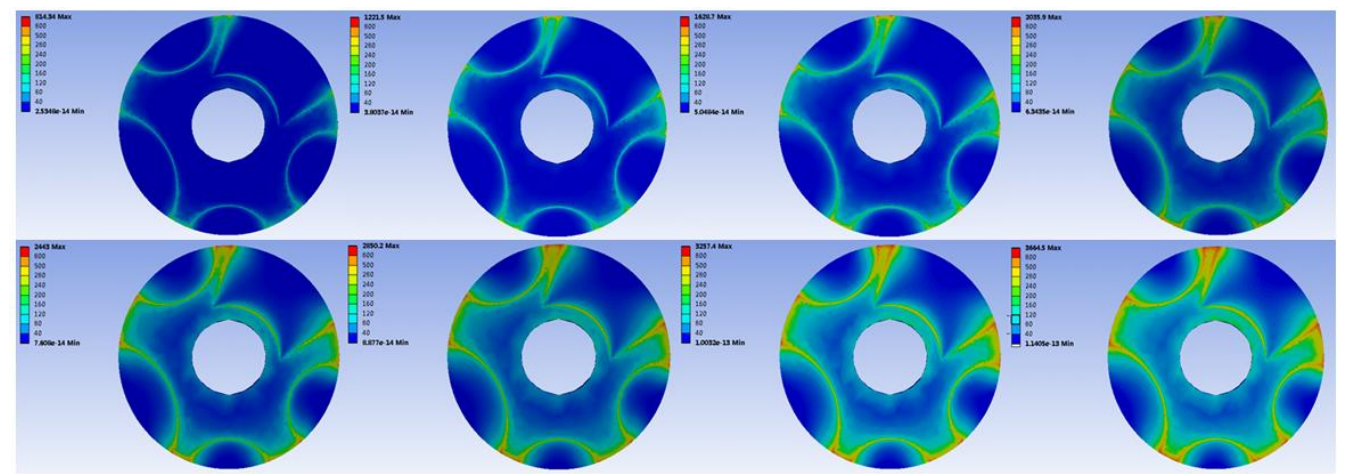

Fig.8 Diagram of the stress under different torque load with similar situation of fracture

\section{Conclusion}

Through analyzing the finite element model in three different conditions (i.e. no crack, circumferential crack, and similar fracture situation of the transmission shaft), a conclusion as follows is drawn up.

First, the cause of the fracture of the transmission shaft at minor-diameter retracting position and reducing position was really not the 
defect of the structural design of the transmission shaft.

Second, serious stress concentration would occur on the tip of crack under the working load if there was a crack on the transmission shaft; the stress on the tip of crack would increase along with the increase of crack depth; the impact from this type of stress concentration on the strength of the transmission shaft was huge, so that the strength of the shaft was greatly reduced.

Third, the main cause of the transmission shaft fracture was the crack generated by the propagation of the defects on the initial surface, and the strength of the shaft was only $1 / 5$ of the original in the fracturing process.

Fourth, the initial cracks always began to propagate from the tip of the external surface of the transmission shaft and then spread inward, and these cracks grew gradually and propagate inward together until the propagating areas of two different cracks overlapped and ultimately reached the position of transient interruption, and then the transmission shaft fractured completely.

Fifth, the impact from the surface defect of the transmission shaft of screw drill on the service life of screw drill was far greater than that from the self-structure of the transmission shaft. Therefore, an enhancement to the detection of transmission shaft defects before screw drill descends into a well is very necessary.

\section{References}

[1] SuYinao. Research and Application of Screw Drill [M]. Beijing: Petroleum Industry Press, 2001.

[2] Huang Xianping, Han Chuanjun, Li Yongbin. Strength Analysis and Optimization Design of the Screw drill Transmission Shaft [J].China Petroleum Machinery, 2011, 39 (S): 25-27.

[3] Liu Huiying. Structural Analysis and Optimum Design of Downhole Motor Based on CAE [D]. Tianjin University of Technology, 2008.

[4] GuoYanru, LianZhanghua, ChenShichun, WeiChenxing, Yangxing. Analysis of Causes for Screw Drill Damage and Fall Well [J]. Journal of Chongqing University of Science and Technology: Natural Science Edition, 2011, 13 (6): 145-147.

[5] XiangGang, LuXiude, Song Dan. Coiled Tubing Drilling and Grinding Process of Screw Motor Characteristics Analysis and Field Application [J]. Drilling \& Production Technology, 2014, 37 (1): 75-77.

[6] HeHuiqun. Coiled-Tubing (CT) Technology and Equipment Development Overview [J].China Petroleum Machinery, 2006, 34 (1):1-6.

[7] Gao Wenquan. Application of Coiled Tubing with Screw Drill Technology in Liaohe Oilfield [J]. China Petroleum Machinery, 2004, 32 (12): 44-45.

[8] Wang Jun. Analysis of Static and Dynamic Characteristics of Screw Drilling [D].Shenyang University of Technology, 2013.

[9] Zhuang Sen , Lu Yinde,WenLigang. Fracture Analysis of the Transmission Shaft of Screw Drill [J]. Heat Treatment of Metals, 2005, 30(6): 88-89.

[10] Dong Hongsheng. Analysis of the Drilling Tool Failure in Northeast Sichuan Area [R]. Shanghai: Drilling Tool in Northeast Sichuan Application Seminar, 2007.

[11] Zhang Zhaohui. ANSYS12.0 Structure Analysis of Engineering Application Examples Third Edition [M]. Beijing: Mechanical Industry Press, 2010.

[12] Su Yinao. The Stress Characteristics of Horizontal Well Screw Drill [J]. Oil Drilling \& Production Technology, 1999, 21 (1): 6-15.

[13] Tian Huijuan, HuYahui, Liu Huiying. Strength Analysis and Optimization Design of the Screw drill Transmission Shaft [J]. Journal of Tianjin University of Technology, 2009, 25 (2): 29-32.

[14] CarpinteriA. Shape Change of Surface Cracks in Round Bars under Cyclic Axial Loading [J].Internari006Fcnal Journal of Fatigue, 1993, 15 (1): 21-26. 
[15] Liang Ge, Ze Hu, Chen Ping et al. Research on Overflow Monitoring Mechanism Based on Downhole Micro-flow Detection [J]. Mathematical Problems in Engineering, Volume 2014.

[16] Liang Ge et al. Research on Distributed Optical Fiber in Oil Well Temperature Field Measurement System, Information
Technology Journal, Volume 12, Number 18, 4651-4654, 2013.

[17] Zhao Guanghui, Wang Haohan, Shi Jian, Zhao Li. Elastic-plastic Fracture Mechanics Analyses of Surface Cracks in Drill Subjected to Combined Loading [J]. Journal of Southwest Petroleum University: Science\& Technology Edition, 2014, 36 (3): 157-164. 